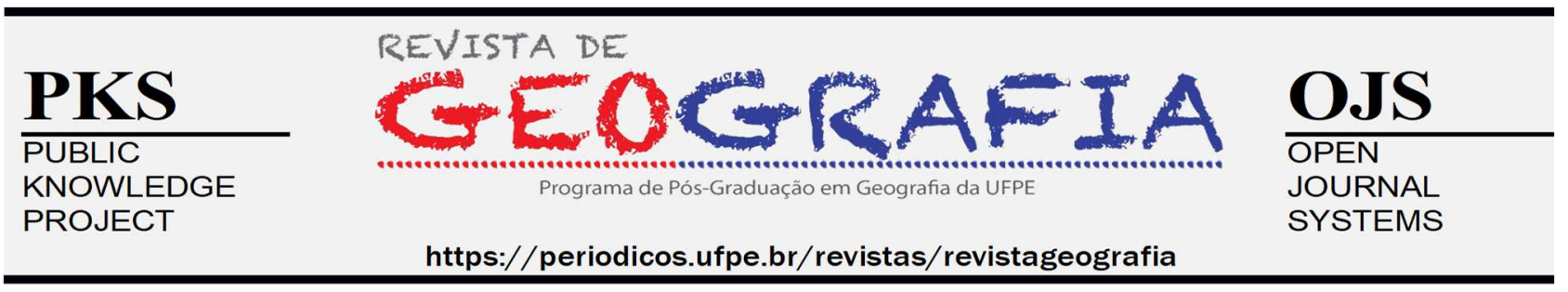

\title{
OS RIOS E O URBANO: RUPTURAS OU CONTINUIDADES NAS CIDADES MÉDIAS DO BRASIL - CHAPECÓ (SC), BRASIL
}

\author{
Janete Facco ${ }^{1}$, Sival Francisco de Oliveira Junior² ${ }^{2}$ Fábio Luiz Carasek ${ }^{3}$, Janete Webler Cancelier ${ }^{4}$, \\ Lisane Regina Vidal Conceição ${ }^{5}$
}

\begin{abstract}
${ }^{1}$ Universidade Federal de Santa Catarina (UFSC), E-mail, janetefacco1@ gmail.com, Orcid: http://orcid.org/0000-00020843-9275

${ }^{2}$ Universidade Federal da Fronteira Sul, E-mail, jr_sival@hotmail.com, Orcid: http://orcid.org/0000-0002-7995-862X

${ }^{3}$ UNOCHAPECÓ, E-mail: fabio_carasek@hotmail.com, Orcid: http://orcid.org/0000-0001-8946-7827

${ }^{4}$ Universidade Federal de Santa Maria (UFSM), E-mail: janetewc@ gmail.com, Orcid: http://orcid.org/0000-0002-48505492

5 Universidade Federal de Santa Maria, Professora da rede estadual e municipal de ensino, E-mail: lisanevidal@gmail.com, Orcid: http://orcid.org/0000-0001-8308-7743
\end{abstract}

Artigo recebido em 19/11/2019 e aceito em 18/03/2021

\begin{abstract}
RESUMO
Este trabalho tem por objetivo compreender as transformações das paisagens de rios urbanos, do município de Chapecó-SC, decorrentes do processo de urbanização. Buscou-se identificar as mudanças ocasionadas na paisagem dos rios, as causas e suas repercussões desde o ano de 1940. Chapecó possui 220.367 habitantes,7\% residentes no rural e 93\% no urbano (IBGE, 2019). O levantamento de dados históricos e imagens dos rios antigos se deu pelo acesso ao acervo do Centro de Memórias do Oeste - CEOM. No decorrer dos anos, a paisagem dos rios urbanos em Chapecó foi alterada, especialmente, pela urbanização desenfreada, sem respeito aos planos originais. A função desses vêm se ajustando as diferentes necessidades dos homens. Alguns fenômenos que se reproduzem em distintos espaços temporais, como sua utilização para canal de escoamento e depósito de resíduos, são reflexos culturais vistos até os dias atuais. A população, em muitos casos, desdenha a presença dos rios, o que ocasionou uma drástica ruptura entre esse patrimônio natural e o espaço urbano. Os resultados demonstram que estes fenômenos estão presentes em Chapecó, muitos rios foram ocultados da paisagem urbana. Diante de tal complexidade, o presente trabalho contribui com informações para o planejamento e tomada de decisão no presente e futuro.
\end{abstract}

Palavras-chave: Rios canalizados; Paisagem urbana; Modificações antrópicas; Reflexos culturais. 


\title{
THE RIVERS AND THE URBAN: BREACHES OR CONTINUITY IN THE MEDIUM CITIES OF BRAZIL - CHAPECÓ (SC), BRAZIL
}

\begin{abstract}
This paper aims to understand the transformations of the landscapes of urban rivers in the municipality of Chapecó-SC, resulting from the urbanization process. We sought to identify the changes caused in the river landscape, the causes and their repercussions since 1940. Chapecó has 220,367 inhabitants, 7\% rural and 93\% urban (IBGE, 2019). The survey of historical data and images of the ancient rivers was given by access to the collection of the Center of Western Memories - CEOM. Over the years, the landscape of the urban rivers in Chapecó has been altered especially by unbridled urbanization, without regard to the original plans. Their function has been adjusting to the different needs of men. Some phenomena reproduce in different temporal spaces, such as their use for drainage channel and waste disposal, are cultural reflexes seen until the present day. The population in many cases disdains the presence of rivers, which caused a drastic rupture between this natural heritage and the urban space. The results show that these phenomena are present in Chapecó, many rivers were hidden from the urban landscape. Faced with such complexity the present work contributes with information for the planning and decision making in the present and future.
\end{abstract}

Keywords: Piped rivers; Urban landscape; Anthropogenic changes; Cultural reflections.

\section{LOS RÍOS Y LO URBANO: RUPTURAS O CONTINUIDADES EN LAS CIUDADES MEDIAS DE BRASIL - CHAPECÓ (SC), BRASIL}

\begin{abstract}
RESUMEN
Este trabajo tiene como objetivo comprender las transformaciones de los paisajes de los ríos urbanos en el municipio de Chapecó-SC, producto del proceso de urbanización. Se buscó identificar los cambios provocados en el paisaje fluvial, las causas y sus repercusiones desde 1940. Chapecó tiene 220.367 habitantes, $7 \%$ rural y 93\% urbano (IBGE, 2019). El relevamiento de datos históricos e imágenes de los ríos antiguos se dio mediante el acceso a la colección del Centro de Memorias Occidentales - CEOM. A lo largo de los años, el paisaje de los ríos urbanos de Chapecó se ha visto alterado especialmente por la urbanización desenfrenada, sin tener en cuenta los planes originales. Su función se ha ajustado a las diferentes necesidades de los hombres. Algunos fenómenos reproducidos en diferentes espacios temporales, como su uso como canal de drenaje y disposición de desechos, son reflejos culturales vistos hasta la actualidad. La población en muchos casos desdeña la presencia de ríos, lo que provocó una ruptura drástica entre este patrimonio natural y el espacio urbano. Los resultados muestran que estos fenómenos están presentes en Chapecó, muchos ríos quedaron ocultos al paisaje urbano. Ante una complejidad como la actual, el trabajo aporta información para la planificación y toma de decisiones en el presente y el futuro.
\end{abstract}

Palabras clave: Ríos canalizados; Paisaje urbano; Cambios antropogênicos; Reflejos culturales. 


\section{INTRODUÇÃO}

Os rios, por onde passam, marcam através de suas curvas a paisagem, se caracterizando como importantes elementos na composição urbana pelas suas funções ambiental e ecológica. São elementos naturais fundamentais desde o início da história da humanidade, sendo que a maioria das cidades se originou às suas margens, principalmente pela sua utilidade. Como resultado, as cidades começaram a incorporar os elementos naturais, entre eles, os rios, a partir de uma visão de ruptura, segundo a qual, a ordem humana imposta ao mundo natural "desordenado" era a simetria e a regularidade, caracterizando uma forma humana de indicar a separação entre cultura e natureza (MARCONDES, 1999, p. 40).

As cidades brasileiras, historicamente, desenvolveram-se acompanhando os leitos dos rios. Entretanto, muitos desses rios passaram por intensas fases de urbanização, processo este, desencadeado sem nenhum tipo de planejamento. Assim, a paisagem desses rios nas cidades brasileiras apresenta-se degradada, como resultado, tem-se rios poluídos pelo depósito de lixo e esgoto, privatização de suas margens, bem como, alterações e retilinizações. Esse fenômeno, ao longo dos anos, se amplia consideravelmente pelo processo de urbanização e pela inter-relação entre as populações e o meio ambiente. Os rios são paisagens naturais, apropriadas e transformadas pela ação cultural do homem. Neste contexto, possuem diferentes significados que se alteram ao longo dos anos (COSGROVE, 1998, p. 109).

O objetivo principal deste trabalho é compreender como ocorreu as transformações das paisagens de rios urbanos de Chapecó-SC entre os anos de 1940-2017. O entendimento desse processo é importante para a reflexão e decisão no planejamento sócio urbano e ambiental, os quais devem ser pensados e executados à luz da preservação dos recursos naturais bem como, da importância, significado e identidade locais.

Para melhor compreender os fenômenos das mudanças que ocorreram nos rios urbanos de Chapecó, sob a perspectiva das transformações espaciais, é importante situá-lo no contexto dos conceitos que sustentam o entendimento dos processos básicos da funcionalidade de como o homem se relaciona com a natureza, o espaço, o lugar, a cultura e a paisagem, bem como articular essa leitura à realidade empírica do espaço pesquisado.

A presença dos recursos naturais, como os cursos d'água, devem ser considerados como potencialidades ao desenvolvimento social das cidades, uma vez que, promove o desenvolvimento ecológico do lugar, contribuindo para um modo de vida mais saudável e promova a materialização de formas naturais na paisagem urbana, contribuindo para a preservação do meio ambiente. Nesse en- 
tendimento, os rios possuem um relevante papel ambiental, cultural e social, pois ao exercerem forte atração, como fontes de recursos as pessoas, determinam a fixação do homem ao lugar e, consequentemente, exercem influências sobre o modo de vida que ali se desenvolve.

A pesquisa caracteriza-se pela abordagem qualitativa. Para seu desenvolvimento, utilizou-se pesquisa bibliográfica, pesquisa documental, pesquisa de campo e análises. Inicialmente, a busca pelo caminho investigativo direcionou-nos pela pesquisa bibliográfica, que procura, de forma sucinta, compreender a relação entre sociedade e a natureza, assim como, caracterizar a área de pesquisa com a leitura de artigos científicos, teses, dissertações e livros relacionados às questões de natureza teórica que abordem a temática.

Num segundo momento, houve a pesquisa documental, o levantamento e a coleta de dados empíricos junto a órgãos públicos qualificados, como o Instituto Brasileiro de Geografia e Estatística (IBGE), Prefeitura Municipal de Chapecó e o Centro de Memórias do Oeste - CEOM, nos arquivos físicos e digitais, essa fase do estudo permitiu acesso a informações sobre a área de estudo e imagens dos rios que estavam presentes.

A necessidade de ampliar a discussão e ter acesso a arquivos de imagens de distintos espaços-tempos do município de Chapecó nos direcionaram para a realização de uma entrevista semiestruturada, a qual ocorreu no ano de 2019 com um fotógrafo que possui um acervo de imagens de Chapecó. A partir das imagens dos rios, principalmente no urbano, foi possível realizar um comparativo com a realidade atual, bem como, compreender a importância do processo histórico na construção da paisagem atual.

\section{A ÁREA DE ESTUDO}

O município de Chapecó foi criado em 1917, sua área territorial corresponde a $624,31 \mathrm{Km}^{2}$. Conta com uma população de 220. 367 habitantes, dos quais, $7 \%$ residentes em área rural e 93\% no perímetro urbano (IBGE, 2019). Na Figura 1, verifica-se a localização do município de Chapecó. 


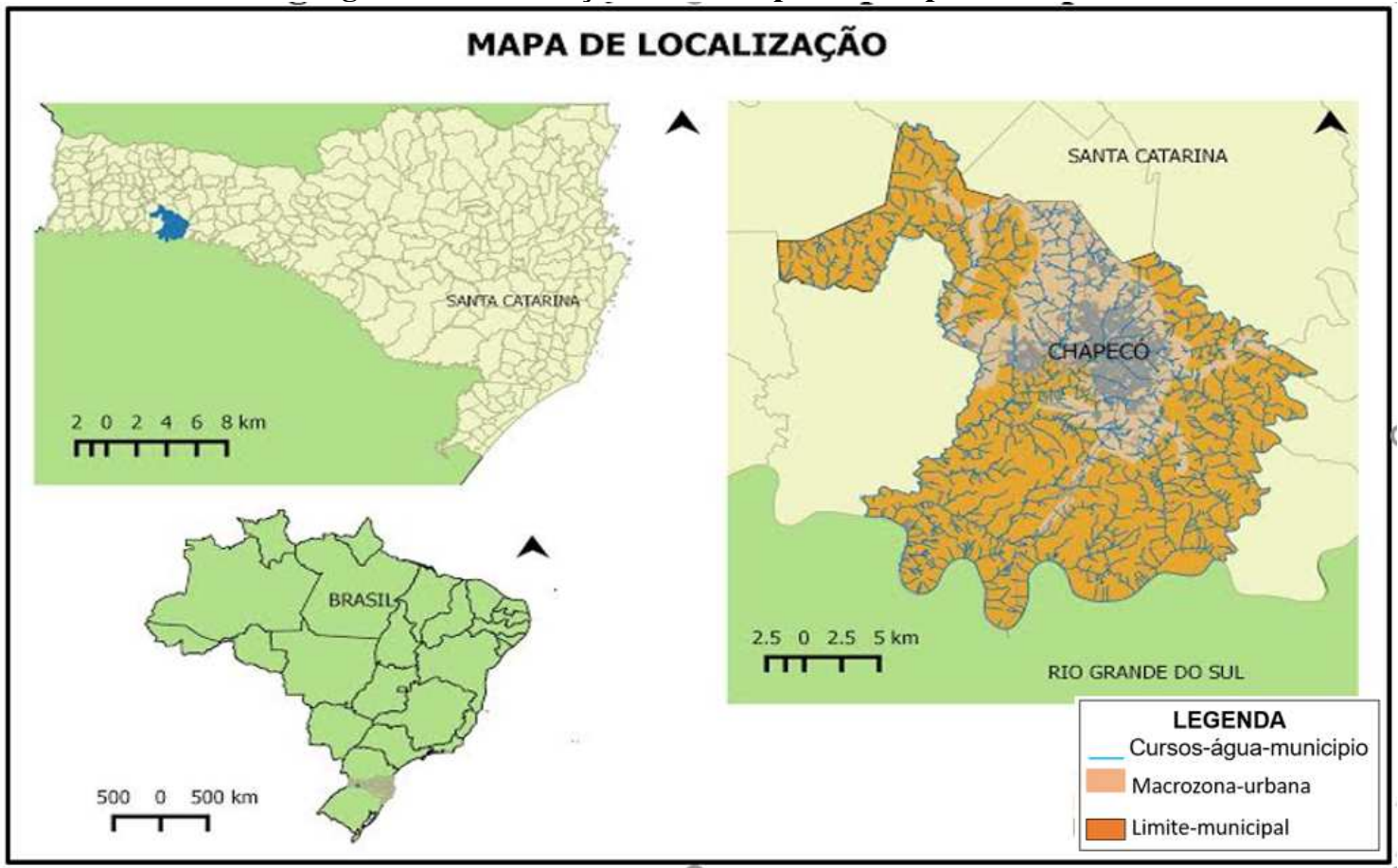

Fonte: Autores, 2019.

Destaca-se que no mapa de localização do município foi dado ênfase aos cursos d'água, ressaltando a parte urbana. Nos primeiros anos de sua colonização a paisagem encontrada era exuberante, tomada por espécies vegetais de grande porte. As quais foram, no decorrer dos anos, sendo removidas, cedendo espaços aos cultivos agrícolas, instalação de indústrias e áreas residenciais. A população existente era pequena e esparsa, suas práticas não alteravam de maneira significativa a paisagem existente da época (CANCELIER, 2007).

Hass (2003), ressalta que, por volta de 1920, os pequenos povoados eram cortados por rios de águas límpidas, quando os primeiros desbravadores chegaram para explorar os recursos naturais, trazendo "o progresso e o desenvolvimento". Durante o processo de colonização ocorreram os ciclos econômicos extrativista, de pecuária, erva-mate, madeira e agroindustrial. "Estes demarcaram a inserção da região no processo global de constituição do mercado nacional, característico do desenvolvimento econômico de caráter urbano industrial do Brasil" (TESTA, 1996, p.62).

Baldissera e Reis (2014), descrevem os diferentes papéis históricos que a água teve na construção do espaço municipal de Chapecó: fonte de alimento, transporte, fonte de energia, local de disposição de resíduos urbanos e industriais, manancial de abastecimento de água potável, turismo e lazer. Ainda, segundo os autores, essas funções interferiram diretamente na configuração socioespa- 
cial presente na realidade urbana do município, influenciando a localização estratégica das atividades e levando a transformações ambientais, atualmente evidenciadas em seu espaço geográfico.

Entre as décadas de 1970 e 1980 ocorreu a "consolidação das agroindústrias no processo de estruturação e transformações no município, fenômeno este decorrente do poder de atração de população migrante, resultando em um acelerado processo de urbanização" (FACCO, 2011, p.72). De acordo ainda com a autora, até a década de 1970, a demanda por água era atendida por poços comuns, escavados, em profundidade média de 12 metros, a quantidade de poços se ampliava acompanhando as taxas de crescimento da população. Porém, não haviam legislações específicas, nem controle municipal para a abertura de poços. A falta de normas possibilitou a ampliação desenfreada de poços, bem como, a contaminação da água dos mesmos. Entre os anos de 1960-1970, com o crescimento da aglomeração urbana, os índices de contaminação, principalmente por coliformes fecais, passam a atingir números cada vez mais elevados.

Todos estes processos, e a necessidade de fornecer água tratada a crescente demanda da população local, levaram a assinatura do primeiro convênio entre a Prefeitura Municipal de Chapecó e a Companhia Catarinense de Água e Saneamento - Casan, no ano de 1973, a partir do qual, a água destinada a população passa a ser captada da barragem do Lajeado São José (WAGNER, 2005).

Até a década de 1970, "os cursos de água do município eram tidos apenas como receptores de efluentes, tanto da população urbana quanto das agroindústrias” (FACCO, 2011, p. 91). Outro elemento levantado pela autora, que corrobora a assertiva, se refere ao fato dos lixões estarem instalados próximos a rios, como exemplo, cita que, a partir do ano de 1980, todo o lixo recolhido no município era depositado a céu aberto, ocorrendo isso até o final dos anos 2000, no Parque das Palmeiras, às margens do Lajeado Passo dos Índios. Posterior a este período passou a ser destinado a um aterro sanitário.

Dentro desta perspectiva, a paisagem está em constante transformação. À medida que o processo de urbanização foi se ampliando, florestas foram derrubadas e rios suprimidos, surgindo espaços destinados a moradia e demais atividades. Tanto as áreas urbanas quanto rurais, apresentam, hoje, outras paisagens, diferentes daquelas do passado, modificadas diariamente, vão se transformando com os novos cenários que vão surgindo. 


\section{RESULTADOS E DISCUSSÕES}

\section{O passado e o presente dos rios e córregos na paisagem urbana de Chapecó}

Atualmente, a população de Chapecó apresenta uma ruptura drástica com seus cursos d'água, um desligamento construído ao longo de sua história. Com grande parte dos córregos subtraídos da paisagem urbana e, com a retirada da vegetação que outrora protegia suas margens, os rios gradativamente foram perdendo sua função ecológica e sua identidade com a cidade (BALDISSERA; e REIS, 2014). Destacando-se ainda, o elevado percentual de contaminação dos recursos hídricos, por falta de esgotamento sanitário, dejetos de animais, resíduos de agrotóxicos e das agroindústrias, dentre outros.

O processo de produção do espaço nem sempre gera paisagens agradáveis, pode gerar sua negação, o que Bertrand e Bertrand (2007), descrevem como sendo a sociedade contra a paisagem. Desse mesmo modo, Gonçalves (2000, p. 3) afirma que, “o Município de Chapecó (SC) se encontra numa situação preocupante com relação ao cumprimento das normas vigentes quanto ao uso do solo e, consequentemente, da água".

Historicamente, a sociedade humana está condicionada à vida social e ao espaço geográfico. A paisagem é a materialização imediata a social e, desse modo, precisa ser analisada no contexto do cotidiano, das representações da natureza e dos seus significados, portanto, as representações da paisagem e da cultura constituem a identidade socioespacial. Neste contexto, a paisagem, como categoria de análise, pode ser historicamente contextualizada por conter as marcas da sociedade ao longo do tempo.

Nesse universo, reporta-se a Berque (2004), que menciona que a paisagem é uma marca, ao denotar uma civilização e também, é uma matriz, porque participa de sistemas de percepção, cuja cultura expressa a relação da sociedade com a natureza e com o espaço. Desta forma, a paisagem é tida como um conjunto de formas naturais e culturais, associadas a uma dada área sendo assim, passível de análise morfológica, observando-se a interação das formas entre si.

Ao objetivar a análise das transformações da paisagem dos rios de Chapecó, observou-se que, para enfrentar a situação crítica gerada pelos altos níveis de contaminação dos mananciais, pela escassez de água no abastecimento das cidades e pelas cheias periódicas, que representavam uma ameaça à saúde e à segurança dos habitantes das cidades, começaram a ser feitas, já na primeira metade do século XX, intervenções de caráter técnico, criando-se, nas paisagens dos rios, feições altamente artificializadas (MELO, 2005). 
Os cursos d'água, desde a antiguidade, foram fundamentais para o surgimento e sucesso de grandes civilizações. As cidades surgiam próximas aos cursos d'água e, no decorrer de diversas fases da história da humanidade, os elementos naturais formadores do espaço geográfico foram intensamente suplantados pela demarcação das construções humanas. Contudo, os elementos naturais, mesmo no urbano, ainda que invisibilizados, permanecem presentes nas cidades, independentemente de sua função, em determinadas situações, se tornam mais visíveis, como é o exemplo dos alagamentos decorrentes das fortes chuvas.

Nesse contexto, Porto-Gonçalves (2014, p. 152), salienta que "a água precisa ser pensada enquanto inscrição da sociedade na natureza, com todas as contradições implicadas no processo de apropriação da natureza pelos homens e mulheres por meio das relações sociais e de poder". O autor ainda relata que "o ciclo da água não é externo à sociedade, ele a contém com todas as suas contradições".

A atual formação territorial de Chapecó é resultante de uma diversidade de fenômenos que se materializaram de distintas formas no espaço. A forma da ocupação inicial e, a não importância aos recursos naturais, acionaram uma série de problemas urbanos ambientais, os quais se refletem na atualidade como uma amarga herança do passado. Reiterando estas afirmativas, Fujita (2008, p.180), salienta que "a inserção progressiva da lógica da (re) produção capitalista ao longo do processo histórico observado na região tem promovido impactos socioambientais expressivos, assim como a geração dos problemas ambientais urbanos nas últimas décadas”.

Os rios representam e delimitam o processo de criação dos primeiros núcleos urbanos, pois há a necessidade de fontes de água para consumo humano, dessedentação animal, além de diversas atividades econômicas e sociais desenvolvidas. Fato esse que torna imprescindível analisar e compreender como se encontra a situação dos córregos (principalmente urbanos - que por isso também são uma ocultação ou negação da própria paisagem) de Chapecó-SC. Entende-se que, "a paisagem urbana reúne e associa pedaços de tempo materializados de forma diversa, autorizando comportamentos econômicos e sociais diversos" (SANTOS, 2001, p. 209).

Ainda que o município de Chapecó apresente um diversificado parque industrial, com frigoríficos, indústrias do ramo metal-mecânico, de plásticos e embalagens, transportes, móveis, bebidas, biotecnologia na industrialização de carnes, software, confecções e outros (IBGE, 2011). Pouco pode ser observado de projetos de recuperação natural dos rios e córregos urbanos, predominando o pensamento de que esses são adversidades ao desenvolvimento. Assim, na maioria das vezes, os gestores 
municipais apresentam como solução aos alagamentos a canalização dos córregos e rios urbanos, extraindo sua presença da paisagem urbana.

As imagens, apresentadas no decorrer do texto, permitem visualizar, comparar o passado e o presente na cidade, bem como, contextualizar a situação de alguns córregos urbanos. A totalidade do fenômeno pesquisado passa a ser compreendida também a partir de uma perspectiva histórico temporal.

Um elemento observado na pesquisa e que merece destaque, se refere as raras fotos que registram cursos d'água, tanto no passado quanto no presente, mesmo que estes fossem utilizados como cenário de fundo para notícias ou registros. Fenômeno este diretamente vinculado a assimilação que os sujeitos possuem da paisagem. Essa lacuna, por parte das autoridades municipais e da população, no decorrer dos anos, se justifica pela percepção ambiental que possuem em relação a importância dos rios no espaço urbano de Chapecó.

Se, por um lado, o acesso aos recursos hídricos, fator de valia no quesito locacional para a instalação das agroindústrias, tem permitido a expansão produtiva e o crescimento econômico da cidade, por outro lado, a urbanização rápida e crescente, tem ocasionado uma diversidade de impactos ambientais diretos e indiretos. Neste caso, reitera-se a importância do poder público e das políticas públicas em seu papel de mediador, proativo e promotor dos interesses coletivos, a fim de minimizar tais impactos (FACCO; e ENGLER, 2017).

$\mathrm{Na}$ cidade de Chapecó/SC, as paisagens naturais, no decorrer do tempo, foram sendo alteradas, ajustadas e adaptadas as demandas urbanas. A partir da Figura 2 (composta pelas fotos 1,2,3,4), visualiza-se, em diferentes temporalidades, no mesmo espaço, o rio Passo do Índios, que corta a cidade no sentido Leste-Oeste, no período de 1940-1978. 


\section{Revista de Geografia (Recife) V. 38, No. 2, 2021}



Fonte: CEOM, 2016.

A partir da figura 2, foto 1, observa-se que no ano de 1940 o rio ainda estava visível, compondo a paisagem natural da região central da cidade. Com o passar dos anos este cenário vai se modificando e, a partir de 1970, inicia-se o processo de canalização de trechos dos rios urbanos, no intuito de minimizar os efeitos adversos das constantes enchentes, conforme fotos números 2,3 e 4 . Desta forma, entende-se que a realocação ajustada dos rios, no contexto urbano, nada mais é do que a canalização do maior número possível de córregos e o abandono de alguns ainda existentes.

Já a Figura 3 (composta pelas fotos 5, 6, 7, 8), demonstra o mesmo rio em forma de canal. A foto 05 , ano de 1974, demonstra o período em que o mesmo se encontra retificado, com canal aberto. 




As fotos 07 e 08, por sua vez, apresentam o chamado "rio do canal", o rio Passo dos Índios, na Rua Benjamin Constant, hoje, o calçadão, este, encontra-se totalmente canalizado e impermeabilizado. A partir da ocultação de seu trajeto natural, diferentes estruturas urbanas foram surgindo, com grandes empreendimentos, como é o caso da loja Havan. Quando um elemento da paisagem urbana é suprimido pela ação e interesses de diferentes agentes territoriais, o mesmo acaba por não mais fazer parte da memória da população residente, tornando-se imperceptível.

A evolução histórica espacial da cidade de Chapecó-SC deixou distintas marcas na paisagem. Até a década de 1970, cada cidadão era responsável pela captação de água, geralmente, através de poços escavados ou tubulares profundos, para atender suas demandas. Não havia preocupação com a preservação dos recursos hídricos, especialmente, os rios. Esta preocupação passa a incidir sobre a população a partir dos anos de 1974, período em que a empresa concessionária responsável pelo abastecimento de água passa a operar na distribuição da mesma. A problemática da distribuição de água tratada à população foi considerada resolvida com a captação de água do Lajeado São José, nesse período.

A partir desta época, agroindústrias, como a Sadia, se instalam no entorno do Lajeado posteriormente o Senai, Celesc, Aurora alimentos e uma série de empresas prestadoras de serviços. Tornando este espaço prioritário para a industrialização e a urbanização nas proximidades. Desta forma, 
"os cursos de água eram tidos apenas como receptores de efluentes das agroindústrias que levavam para longe os resíduos, fato este descrito no Plano Diretor de 1974" (FACCO, 2011, p. 91).

A Figura 4 (composta pelas fotos 09, 10, 11, 12), apresenta a represa Engenho Braun, utilizada, inicialmente, para geração de energia elétrica. A partir de 1974 passou a ser o ponto de captação de água para abastecimento público da cidade, formada pelas águas do Lajeado São José.

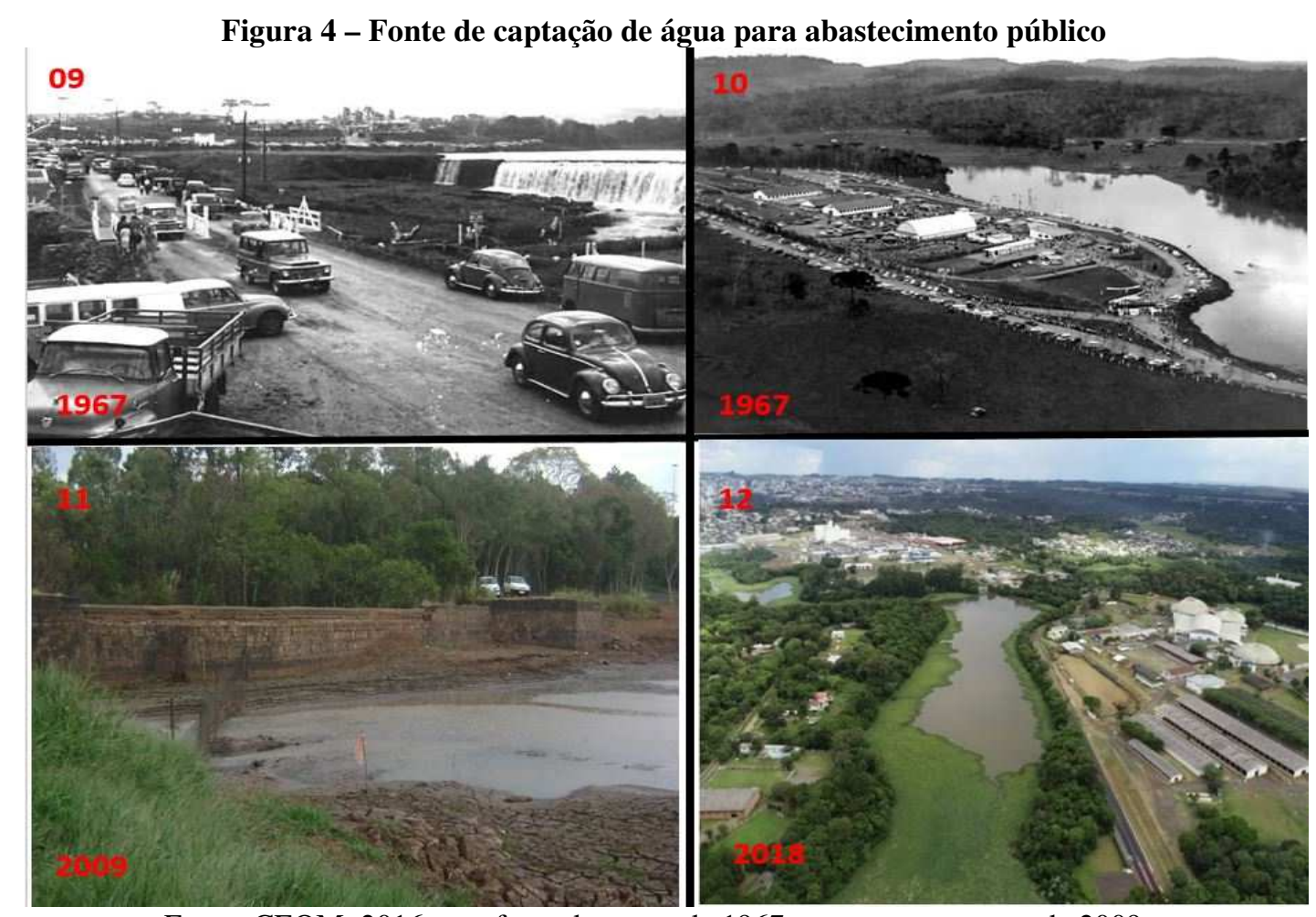

Fonte: CEOM, 2016 para fotos dos anos de 1967; autores para o ano de 2009 e Prefeitura Municipal de Chapecó, ano de 2018.

A partir de foto 11, percebe-se que a paisagem sofreu significativas alterações em decorrência de uma estiagem ocorrida no ano de 2009, ocasionando a diminuição expressiva no volume de água da represa. E, na foto 12 , um panorama do lago, formado pelas águas desse mesmo Lajeado envolto pela urbanização, com acentuado processo de assoreamento.

Por sua vez, na Figura 5 (composta pelas fotos 13, 14, 15, 16), estão presentes elementos da paisagem, como a Frecooper (foto 13), primeira cooperativa de grãos e insumos do município, localizada nas proximidades de um curso d'água, a qual utilizava-se dessa água. O mesmo local, atualmente (foto 14), é ocupado por uma unidade da Aurora Alimentos, a qual também se utiliza da água do rio para realizar as atividades de limpeza. No ano de 2018, ocorreram chuvas torrenciais, provocando 
alagamentos. O que demonstra que, canalizar um recurso hídrico, por si só, não resolve a problemática recorrente das enchentes urbanas, de forma geral.

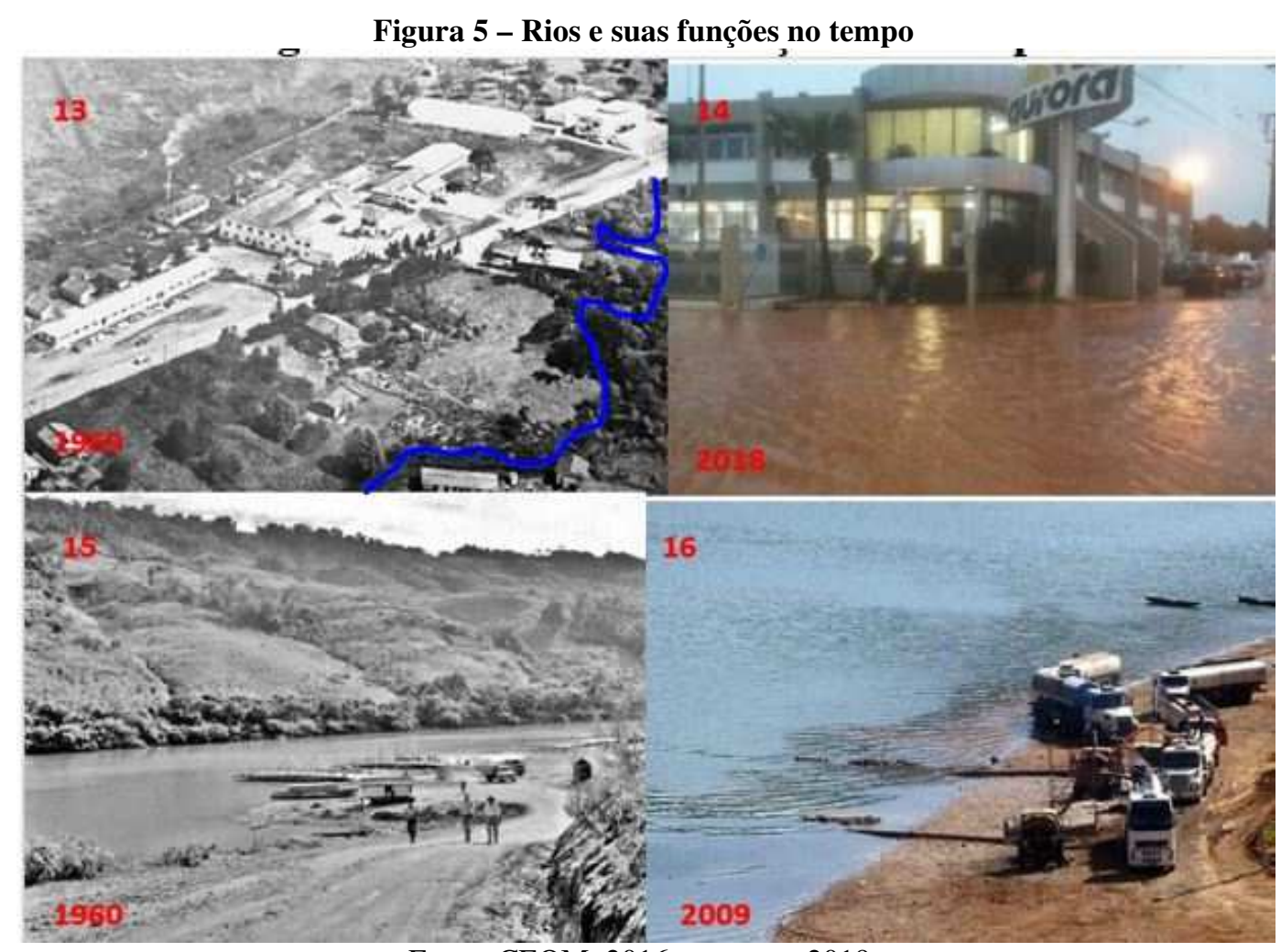

Fonte: CEOM, 2016 e autores, 2019.

(A cor azul representa os córregos/rios, canalizados ou não nas paisagens).

Já a foto 15 , demonstra uma balsa no porto Goio-en, rio Uruguai, divisa entre os Estados de Santa Catarina e Rio Grande do Sul, a qual fazia a travessia de carros e pessoas. Na foto 16, ano de 2009, observa-se caminhões captando água no leito do rio Uruguai, esta usada para atender as demandas de abastecimento público e da Sadia, ficando a encargo dessa empresa, a responsabilidade pelos custos do transporte no período da estiagem (outubro/novembro). A concessionária de água e a empresa efetivaram uma parceria, onde $40 \%$ da água captada e tratada no rio Uruguai seria disponibilizada para a linha de produção da empresa e, os $60 \%$ restantes, para a sociedade.

Sequencialmente, a Figura 6 (composta pelas fotos 17, 18, 19, 20), apresenta distintas paisagens urbanas enfatizando a presença dos rios. 


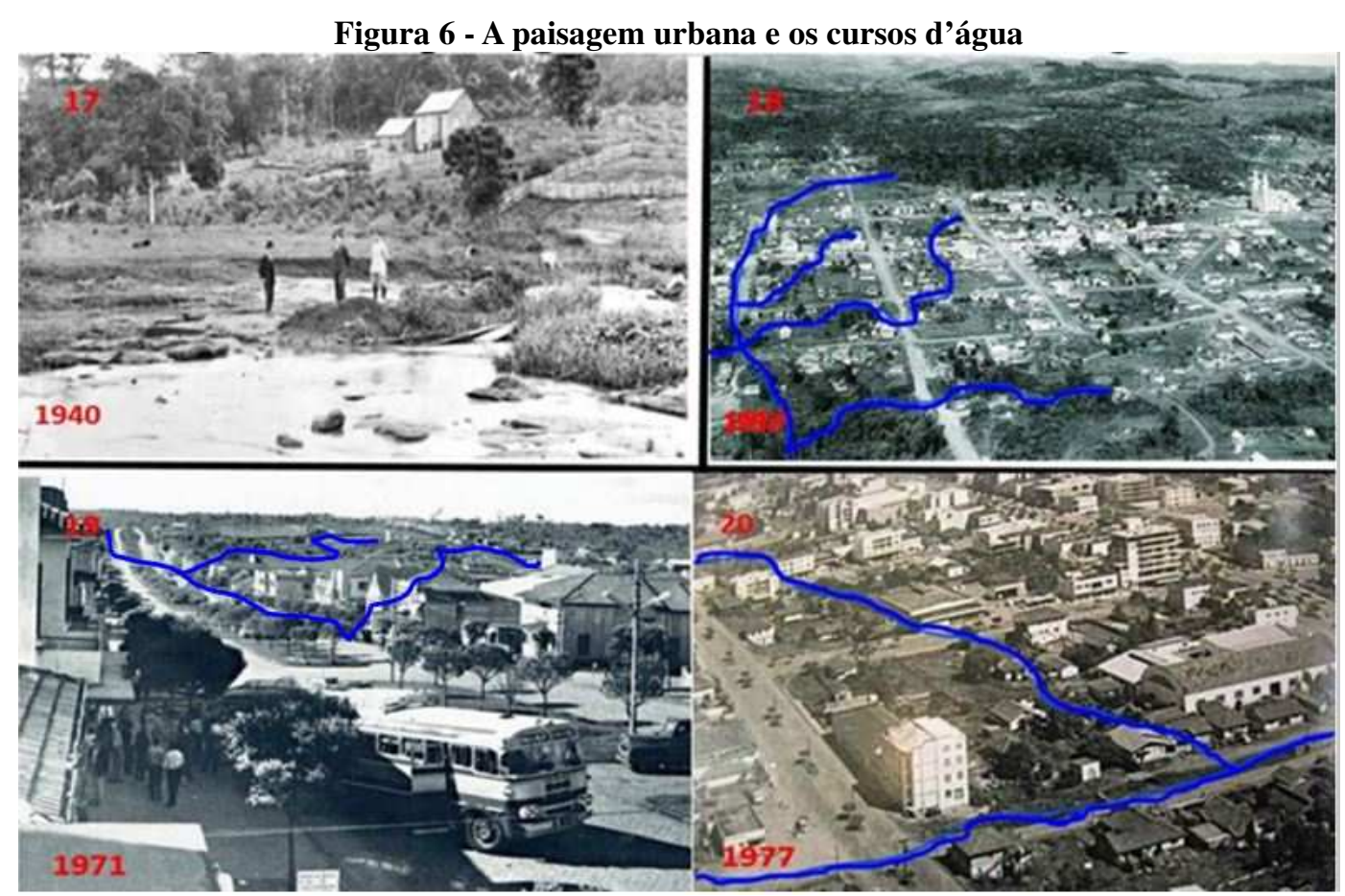

Fonte: CEOM, 2016 (A cor azul representa os córregos/rios, canalizados ou não nas paisagens).

As fotos 17 e 18, estampam vistas parciais do urbano de Chapecó a partir de 1940, período que se caracterizava pela pouca impermeabilização dos espaços e a presença da vegetação entre as construções, o que permitia a infiltração das águas das chuvas no solo e, consequentemente, facilitava a recarga do Sistema Aquífero Serra Geral, principal fonte de água subterrânea explorada no município. Por sua vez, as fotos 19 e 20, mostram um panorama parcial da cidade, com desenho dos córregos que a cortam (identificados com traçado azul), em sua grande maioria, canalizados (já na década de 1970). Os espaços anteriormente ocupados pelos cursos d'água foram excluídos da paisagem urbana, dando espaço as ruas e edificações.

Neste contexto, os rios invisibilizados perante a população urbana, passam a ser utilizados como pontos de descarga de esgotamento doméstico. Nicolai (2001) diz que a água, como um bem econômico no território de Chapecó, é um recurso finito e vulnerável, essencial para a sustentação da vida, que requer uma gestão efetiva através de ações integradas e participativas que protejam os ecossistemas naturais e, ao mesmo tempo, propiciem o desenvolvimento social e econômico, com a proteção dos ecossistemas naturais. No que diz respeito a presença dos cursos d'água na atual paisagem urbana na cidade de Chapecó-SC, observa-se que são poucos os pontos em que se encontram de forma natural, sofrendo forte pressão pela canalização. 
A Figura 7 (composta pelas fotos 22, 23, 24), demonstra pontos de alagamentos no ano de 2018, em bairros da cidade onde os rios foram suprimidos pelas edificações.



Fonte: G1 Santa Catarina (internet), 2018.

As fotos 22, 23 e 25 se referem aos bairros Eldorado, Passo dos Fortes e Pinheirinho, pontos onde ocorrem constantes alagamentos. Processo esse recorrente das canalizações, que não foram dimensionadas para receber a ampliação das áreas de contribuição, advindas de novos parcelamentos do solo. Além disso, destaca-se que, parte dessas canalizações, é obstruída por lixo e entulho depositados pela população. Por sua vez, a foto 24 demonstra o Ecoparque, localizado no centro da cidade, que é um parque onde as pessoas caminham ao ar livre, essa área margeia um curso d'água. Como a demanda não consegue ser suprimida pela vazão da canalização, a água tende a acumular-se nos locais onde os córregos estão abertos, ocasionando os recorrentes alagamentos na região.

A Figura 8 (composta pelas fotos 26, 27, 28, 29), evidencia as paisagens urbanas de Chapecó com a presença de rios. 


\section{Revista de Geografia (Recife) V. 38, No. 2, 2021}

Figura 8 - Rios e as paisagens urbanas

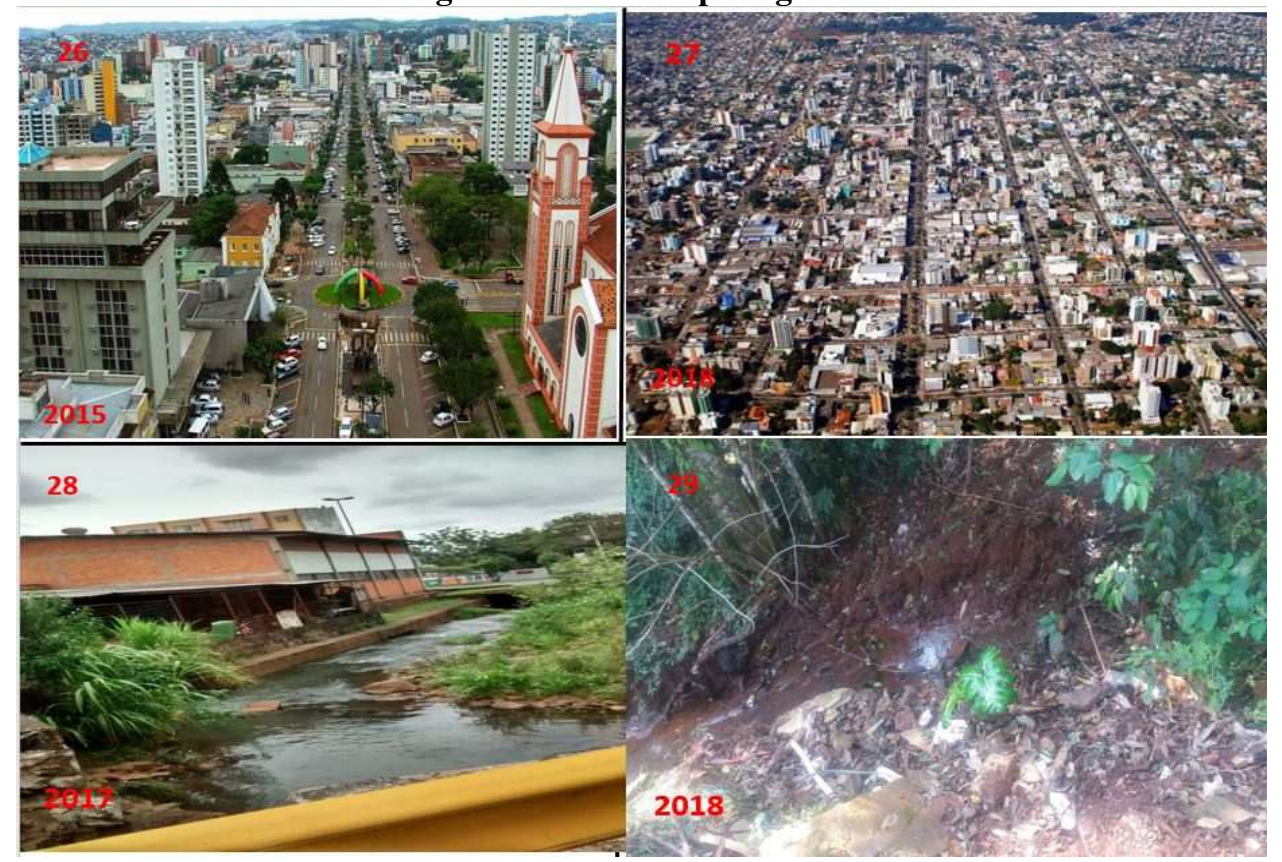

Fonte: Prefeitura Municipal de Chapecó (2018) e autores (2019).

As fotos, 26 e 27, mostram um panorama parcial da avenida Getúlio Vargas, centro da cidade, sentido norte/sul, densamente edificado e a impermeabilização do solo urbano, o que dificulta a infiltração das águas das chuvas e, somado isso à canalização dos cursos d'água, resulta-se em alagamentos sempre que ocorrem chuvas mais intensas. As demais fotos, desta figura, demonstram intervenções nas formas de ocupação do espaço, impactando diretamente nos cursos d'água, seja na forma de assoreamento ou ocupação das margens.

A Figura 9 (composta pelas fotos 30, 31, 32, 33), evidencia os córregos e os efeitos da antropização. 


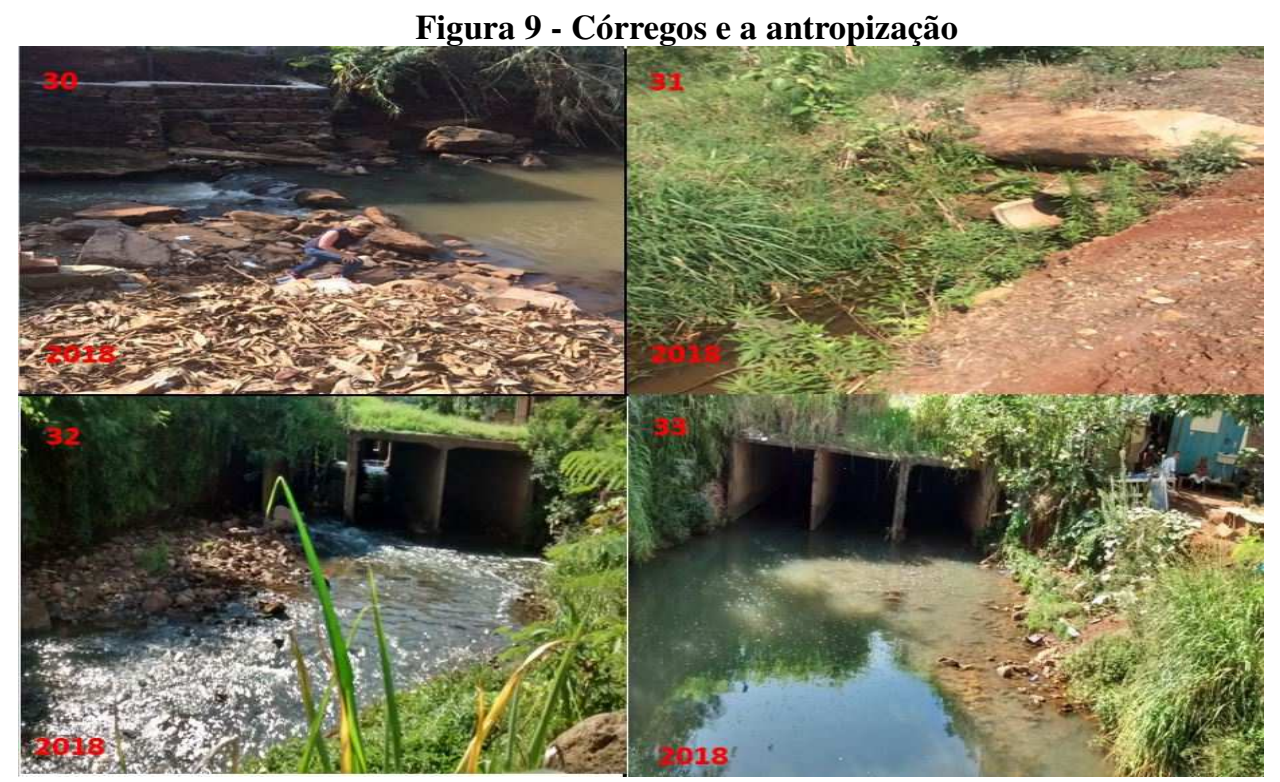

Fonte: autores, 2018.

As fotos 30 a 33, são córregos que cortam a cidade de Chapecó-SC, destaque para a foto número 31, no loteamento Vila Zonta, assoreado, em parte canalizado, aterrado e sem mata ciliar em decorrência da implantação de um novo loteamento. A foto 33 aponta para residência construída de forma irregular no leito do córrego com despejo de lixo na sua lateral, a água turva é decorrente de um "lava-car" implantado no leito do rio, sem nenhum tratamento prévio das águas residuais desta atividade antes da disposição final no rio.

De acordo com os apontamentos de Porto-Gonçalves (2011, p. 18), “a problemática ambiental tem desafiado universidades e pesquisadores, pois trata-se de um novo tipo de crise, sobre a qual ainda não há uma teoria crítica”. Para o autor, vivemos uma ‘crise de caráter civilizatório' - o que supõe que algo precisa começar imediatamente na prática para surtir efeitos em médio e longo prazo. Isso porque essa 'crise' relaciona-se diretamente com as atitudes de cada cidadão, com a cultura das pessoas e, para mudar, faz-se necessária uma reeducação na relação do homem com o espaço 'natural'.

A disputa pelos espaços da água pode ser observada a partir da Figura 10 (composta pelas fotos $34,35,36,37)$. 


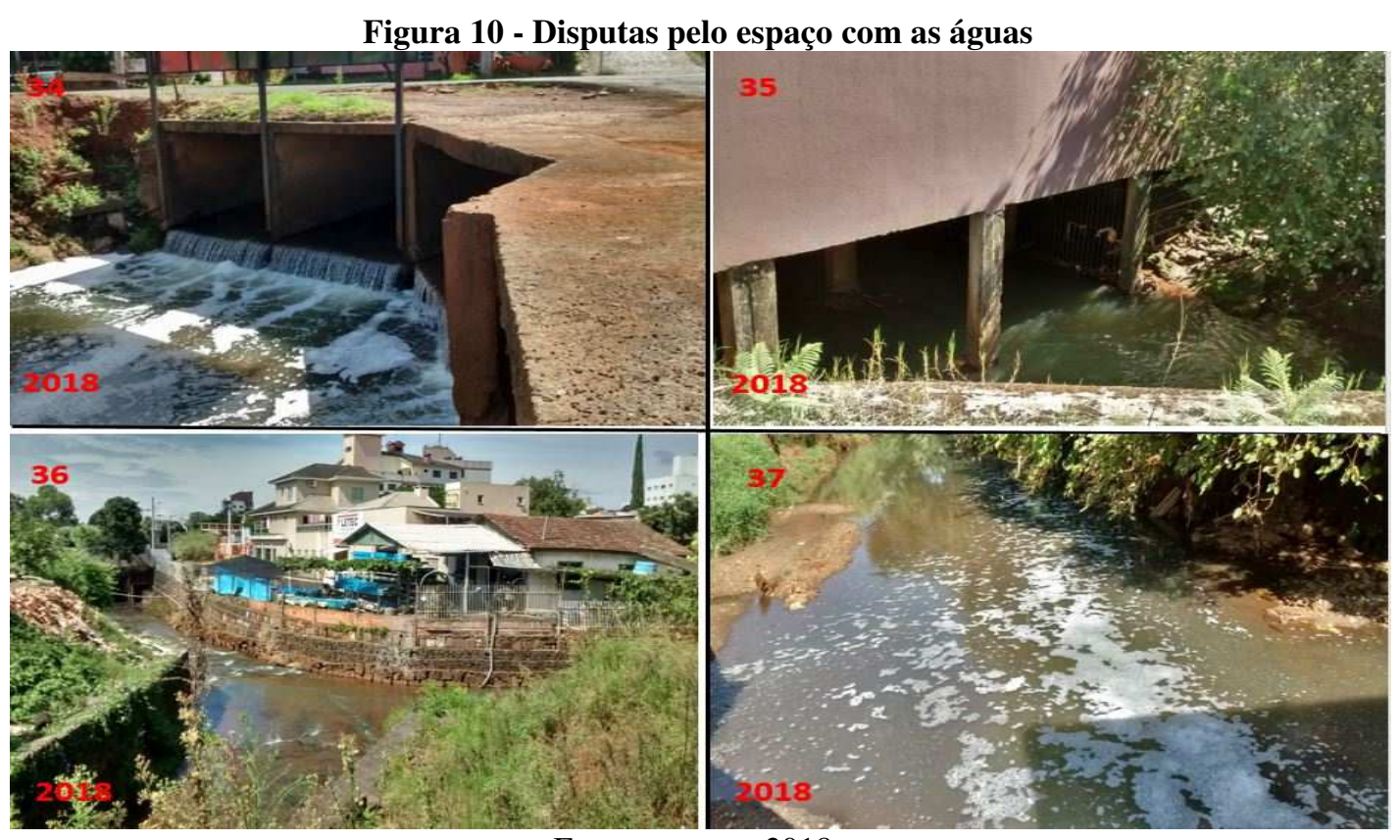

Fonte: autores, 2018.

As fotos 34 e 36 apresentam a união de dois ou mais córregos em pontos diferentes da cidade, ainda possíveis de serem vistos, os muros de contenção não substituem a mata ciliar, mas servem de "proteção" para as residências do entorno. A foto 35 traz um prédio construído sobre o rio, certamente com a conivência das autoridades competentes. Já na foto 37, outro curso d'água no bairro Saic, o qual apresenta visíveis sinais de poluição e assoreamento das margens.

Em todo o contexto apresentado observa-se que a sociedade vem ao longo dos anos perdendo a relação física e visual com qualquer corpo d'água na área urbana de Chapecó (BALDISSERA; e REIS, 2014). Os mesmos autores ainda salientam que, com a abstração dos córregos da paisagem urbana, somado com a ausência de atividades e atrativos relacionados ao uso de suas Áreas de Preservação Permanente - APPs, os rios perderam sua função ecológica e sua identidade com a cidade. A partir da Figura 11 (composta pelas fotos 38, 39, 40, 41), observa-se a paisagem atual dos rios urbanos na cidade de Chapecó. 


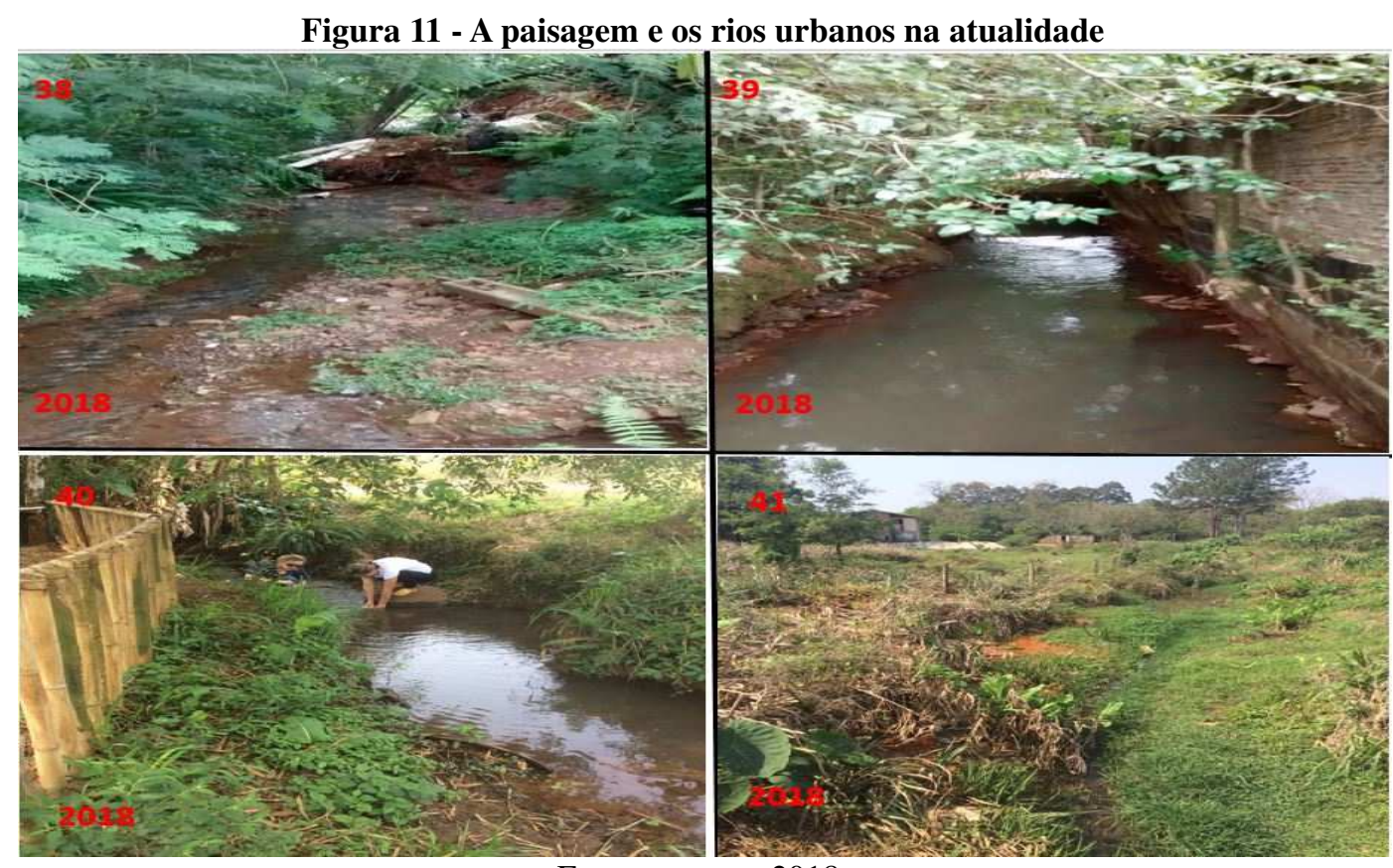

Fonte: autores, 2018.

A partir da foto 38 é possível visualizar o córrego que corta o bairro Esplanada, o qual possui um aterramento irregular e despejo de rejeitos de construção, o que tem dificultado a passagem da água. Já a foto 39, apresenta um muro no leito direito do rio, fazendo a delimitação com o terreno, no centro da cidade. A foto 40 é um curso d'água no bairro São Pedro, região leste da cidade, apresentando um cenário de assoreamento e poluição. E, na foto 41, resquícios do córrego no bairro Pinheirinho, totalmente assoreado, recebendo esgoto doméstico, tonalidade da água laranja. Importante relatar que esse córrego se localiza num espaço que era conhecido, até recentemente, como a "rua dos açudes", justamente porque era uma chácara que possuía diversos açudes (pesca esportiva).

Há aproximadamente cinco anos, com a implantação de novos loteamentos, os açudes foram aterrados, o córrego foi canalizado em sua grande extensão e as construções não respeitaram nem a nova faixa de Área de Preservação Permanente - APP do canal. "Na visão economicocêntrica, os bens ambientais não são idealizados como recursos esgotáveis; pelo contrário, são reduzidos ao proveito econômico ilimitado" (DALLA CORTE, 2013, p. 34).

\section{Planos Diretores de Chapecó e as questões ambientais}

A análise dos Planos Diretores se faz importante, na medida em que permitem compreender as formas de uso e ocupação do solo urbano e como estes fenômenos repercutem sobre o meio natural. O município de Chapecó teve quatro Planos Diretores: o Plano de Desenvolvimento Urbano de 
1974, Plano Diretor Físico-Territorial de 1990, Plano Diretor de Desenvolvimento Territorial de 2004 e o atual Plano Diretor de Chapecó, publicado em 26 de novembro de 2014 (Lei Complementar N ${ }^{\circ}$ 541/2014).

A legislação ambiental e a urbana, ao longo dos anos, sofreram avanços e retrocessos, refletindo em sua aplicabilidade. Dificilmente, no decorrer das décadas, houve uma efetiva fiscalização pelos órgãos competentes. Neste contexto, um dos principais problemas passa a ser a desarticulação entre a gestão ambiental e a gestão urbana (BALDISSERA; e REIS, 2014).

Fomentar estudos que envolvam a dinâmica dos usos diários da água numa perspectiva que mostre a importância desse recurso natural a todas as formas de vida numa determinada região tornase essencial para promover a qualidade de vida e economia sustentável dos sistemas vivos em uma bacia hidrográfica, é o que Porto-Gonçalves (2014) aponta como necessário.

No que se refere, especificamente a questão ambiental, a partir do ano de 2000, se enaltece a preocupação em relação à proteção dos recursos naturais, passando a reconhecer a importância desses recursos e definindo restrições para sua utilização e ocupação (FUJITA, 2008).

Há falta de ações efetivas relacionadas as questões ambientais, a exemplo dos córregos que estão deixando de fazer parte do desenho da cidade, através das canalizações, aterro de banhados, assim como uma carência de parques onde a população possa desfrutar de momentos de lazer e para prática de esportes com a família (FACCO; ENGLER, 2017).

O grande atraso na efetiva materialização de uma gestão integrada, participativa e coerente dos recursos hídricos (planos de bacia, cadastros, outorga, etc.) no Oeste Catarinense, onde Chapecó se insere, faz com que estas situações se agravem. A grande desproporção de responsabilidade e apoio (no que se refere à gestão da água) entre a sociedade, o poder público e as grandes empresas ocasionam o uso indevido dos rios, bem como, o despejo de efluentes e águas residuais, comprometendo ainda mais a capacidade de autodepuração dos mesmos.

Observa-se que, apesar de presentes as Políticas Públicas, entre elas o Plano Diretor, não se materializam de forma concreta, desarticulando ações, desconsiderando a necessidade de pensar no uso do solo e nas águas superficiais, subterrâneas e na infraestrutura hídrica (FREITAS, 2015).

Estudos com enfoque ambiental tornam-se fundamentais para diagnosticar uma determinada realidade e auxiliar na construção de Políticas Públicas para preservação e gestão integrada da qualidade e quantidade das águas em uma bacia hidrográfica.

Chapecó possui, em seu território, paisagens distintas, antropizadas, fundamentadas, principalmente, no processo de urbanização, agroindustrialização e nas atividades agrícolas e agropecuárias, 
onde os fatos, processos e ações são causas e consequências das modificações na paisagem desse território.

Tais problemas refletiram diretamente na quantidade e, principalmente, na qualidade das águas superficiais disponíveis na região. A demanda de água em Chapecó acompanha o crescente processo de urbanização, sendo perceptível o aumento pela busca da água subterrânea, que passou a ser a alternativa, acarretando um grande crescimento no número de perfurações de poços tubulares. A partir do contexto apresentado, concorda-se com Freitas et al. (2003, p. 4), o qual sinaliza que "hoje o desenvolvimento econômico e social da região depende fundamentalmente do recurso hídrico subterrâneo".

\section{CONSIDERAÇÕES FINAIS}

A partir desta análise sobre os rios que compõem a paisagem urbana de Chapecó (SC), foi possível compreender como as mudanças vem se materializando em distintos tempos.

Evidencia-se a necessidade de um maior comprometimento da sociedade bem como, dos gestores públicos na preservação dos recursos naturais, entre os quais, os rios. Entre os fatores observados está o processo de ocultação dos rios urbanos. Sua invisibilidade, no atual momento, faz parte da identidade da cidade. A paisagem dos rios no urbano está presente apenas na memória dos moradores mais antigos e nos acervos.

Em períodos de intensas chuvas, as paisagens ocultadas se colocam presentes, a partir das enchentes e alagamentos, se tornam visíveis perante a sociedade, porém, são vistas de forma negativa. O rio, que outrora foi canalizado, que perdeu seu percurso natural, passa a ser nominado enquanto um problema, nesta conjuntura. A falta de planejamento urbano na gestão do território possibilitou o crescimento desordenado da cidade, o que, por sua vez, reflete no atual cenário urbano ambiental.

Percebe-se, que ao longo do tempo, a paisagem dos córregos e rios urbanos em Chapecó foi alterada especialmente pela urbanização desenfreada, que não respeitou seus traçados. Fica evidente que a função dos rios no passado foi para servir de canal de escoamento do que não era necessário à população, o que se reflete culturalmente nos dias atuais, visto que a população, em muitos casos, desdenha a presença do rio. Este fato talvez seja justificado por muitos destes rios terem sido ocultados da paisagem no município de Chapecó.

Salienta-se a necessidade de um trabalho no sentido educacional para que, distintos atores sociais e políticos, identifiquem os rios como elementos da paisagem urbana, construindo, neste contexto, uma relação de pertencimento. Fenômeno este já salientado por Yi-fu Tuan (1974), quando 
destaca sobre a presença de rios na paisagem urbana, inclusive para a revitalização de espaços, a fim de melhorar as condições ecológicas e de qualidade de vida da população.

Considera-se essencial que ocorra a reinserção dos rios nas paisagens urbanas, redefinindo seu papel, demonstrando sua importância enquanto um elemento natural essencial a todas as formas de vida.

\section{REFERÊNCIAS}

BALDISSERA, A. D.; REIS, A. F. A cidade e as águas - Chapecó e a microbacia do lajeado São José. In: III seminário Nacional sobre o Tratamento de Áreas de Preservação Permanente em Meio urbano e Restrições Ambientais ao Parcelamento do Solo. APP Urbana 2014. UFPA - Belém, 10 a 13 de setembro de 2014. 16 p. Disponível em: http://anpur.org.br/appurbana2014/anais/ARQUIVOS/GT5-160-23-20140516222259.pdf. Acesso em 10-08-2018.

BERQUE, A. Paisagem-Marca, Paisagem-Matriz: Elementos da Problemática para uma Geografia Cultural. In: CORRÊA, R.L.; ROSENDAHL, Z. Paisagem, tempo e cultura. 2 eds. Rio de Janeiro: EdUERJ, 2004.

BERTRAND, G.; BERTRAND, C. Uma geografia transversal e de travessias: o meio ambiente através dos territórios e das temporalidades. Organizador Messias Modesto dos Passos. - Maringá: Massoni, 2007. 332 p.

CANCELIER, J.W. A agricultura familiar como agente produtora do espaço rural no município de Chapecó-SC. 2007. 147 f. Dissertação (Mestrado em Geografia) - Universidade Federal de Santa Catarina, Florianópolis, 2007.

CHAPECÓ. Lei Complementar no 541, de 26 de novembro de 2014. Aprova o Plano Diretor de Chapecó - PDC. Chapecó, 2014._Disponível em: https://leismunicipais.com.br/a1/plano-diretorchapeco-sc. Acesso em 21-04-2019.

COSGROVE, D. A Geografia está em toda parte: Cultura e simbolismo nas Paisagens Humanas. In: Paisagem, Tempo e Cultura. (Org.) Corrêa, R. L. et al. Rio de Janeiro, EdUER: .1998. pp. 92-123.

DALLA CORTE, T. Direito Humano e patrimônio da humanidade: a evolução no tratamento jurídico da água. Revista Catalana de Direito Ambiental - RACO - Vol. 4, N. 2: 2013. Disponível https://www.raco.cat/index.php/rcda/article/view/273855. Acesso 13-10-2018.

FACCO, J. Os conflitos ambientais no processo de urbanização na bacia hidrográfica de abastecimento de água de Chapecó-SC. 231 f. Dissertação (Mestrado em Ciências Ambientais) - Unochapecó.- Chapecó (SC): 2011.

FACCO, J.; ENGLER, J. M. O processo histórico de urbanização de Chapecó (1950-2016) - Notas sobre: a ocupação urbana, os planos diretores e os conflitos ambientais. P. 287- 324. In: Chapecó em Foco: textos e contextos sobre o espaço urbano regional. (e-book). NASCIMENTO, Ederson; VILLELA, Ana L. V. (Orgs). São Carlos: Pedro \& Paulo, 2017. 597p. ISBN: 978-85-7993-388-2. 
FREITAS, M. A. et al. Diagnóstico dos recursos hídricos subterrâneos do oeste do estado de Santa Catarina: Projeto Oeste de Santa Catarina/PROESC. Porto Alegre: CPRM/SDM-SC/SDASC/EPAGRI. 2003. 100 p.

FREITAS, M. Estiagem no Oeste Catarinense: diagnóstico e resiliência. Projeto de Pesquisa Desenvolvido pela Universidade do Estado de Santa Catarina (UDESC) em parceria com a Secretaria de Estado de Proteção e Defesa Civil de Santa Catarina (SDC). Laboratório de Estudos em Redução de Risco de Desastre (LabRED), o Laboratório de Geoprocessamento (GeoLab) e o Laboratório de Planejamento Urbano e Regional (Labplan). - Florianópolis, 2015.

FUJITA, C. Dilema urbano-ambiental na formação do território brasileiro: desafios ao planejamento urbano no Brasil. Tese (Doutorado Paisagem e Ambiente) - FAUUSP, São Paulo, 2008.

GONÇALVES; O. C. L. Uso e ocupação do solo na microbacia do lajeado São José - Chapecó/SC e seus reflexos na qualidade da água. Dissertação (Mestrado em Geografia): Universidade Federal de Santa Catarina. Florianópolis, 2000.

HASS, M. O linchamento que muitos querem esquecer: Chapecó, 1950-1956. ed. rev. Chapecó: Argos, 2003.

IBGE. Instituto Brasileiro de Geografia e Estatística. Contagem da População. Chapecó-SC (2011). Disponível em: http://www.ibge.gov.br. Acesso em: 20 set. 2018.

Contagem da população - Chapecó-SC. Estimativa para 2019 (2019). Disponível em: http://www.ibge.gov.br/home/estatistica/populacao/censo2010/tabelas_pdf/total_populacao_santa_cat arina.pdf. Acessado em 10/03/2019.

MARCONDES, M. Cidade e Natureza: proteção dos mananciais e exclusão social. São Paulo, Edusp: 1999.

MELO, V. M. Dinâmica das paisagens de rios urbanos. XI Encontro Nacional da Associação Nacional de Pós-Graduação e Pesquisa em Planejamento Urbano e Regional - ANPUR. Salvador -BA, 23-27 maio de 2005. Disponível http://www.xienanpur.ufba.br/334.pdf. Acessado em 10/03/2019.

NICOLAI, G. Avaliação das concentrações de nitratos na água subterrânea do município de Chapecó - SC. 2001. 89 f. Dissertação (Mestrado em Engenharia Ambiental) - Universidade Federal de Santa Catarina, Florianópolis, 2001.

PORTO-GONÇALVES, C. W. O desafio ambiental. (2014). Rio de Janeiro: Record. 179 p.

PORTO-GONÇALVES, C. W. Sociedade e Natureza. Sociedade é natureza. In: Bacia Hidrográfica do Rio do Peixe: Natureza e Sociedade. TREVISOL, Joviles V.; SCHEIBE, Luiz F. (Org). - Joaçaba: Unoesc, 2011. 394 p.

SANTOS, M. A natureza do espaço: espaço e tempo: razão e emoção. 3 ed. São Paulo: Editora da Universidade de São Paulo, 2001. 384 p. 
TESTA, V. M. et al. O desenvolvimento sustentável do Oeste Catarinense (Proposta para discussão). Florianópolis: EPAGRI, 1996.

TUAN, Yi-Fu. Topofilia: um estudo da percepção, atitudes e valores do meio ambiente. São Paulo: DIFEL, 1974. 288 pp.

WAGNER, A. E... Chapecó levantou vôo. Florianópolis: De Letra, 2005. 